\title{
PENGARUH PEMAHAMAN SISTEM INFORMASI AKUNTANSI, MOTIVASI, DAN DISIPLIN KERJA TERHADAP KINERJA PEGAWAI BAGIAN KEUANGAN SATUAN KERJA PERANGKAT DAERAH (SKPD) KABUPATEN TULUNGAGUNG
}

\author{
Faradila Pratiwiningtyas*, Adi Prasetyo \\ Progam Studi Akuntansi Fakultas Ekonomi dan Bisnis \\ Universitas Muhammadiyah Malang \\ Jl. Raya Tlogomas No. 246 Malang \\ *Corresponding author: faradilapratiwiningtyas@gmail.com
}

Diterima 25 Agt 2018

Direviu 28 Agt 2018

Direvisi 30 Sep 2018

Diterima 12 Okt 2018

Artikel ini tersedia di website :

http://ejournal.umm. ac.id/index.php/jaa

\section{ABSTRACT}

This research aims to demonstrate the effect of understanding accounting information systems, motivation, and work discipline on employee performance. The population in this research is the department at regional units of Tulungagung regency. The sample in this research is the finance department employee of Tulungagung regency. The variable in the research independent variables is understanding accounting information systems, motivation, and work discipline, the dependent variable in the employee performance. Data were analyzed using double linear regression. Data were analyzed using SPSS. The results show that the understanding accounting information system has no significant effect on employee performance. This is evidenced by probability value ( $p$ value) 0,263 on the significant 0,05. The results of research next are motivation and work discipline significant effect on employee performance. This is evidenced by probability value ( $p$-value) 0,005 and 0,001 on the significant 0,05.

Keywords: Motivation, Understanding accounting information systems, The employee performance, Work-Discipline

\section{PENDAHULUAN}

Sumber daya manusia merupakan penggerak utama jalannya kegiatan sebuah organisasi, maju mundurnya suatu organisasi ditentukan oleh keberadaan sumber daya manusianya. Sehingga sumber daya manusia atau pegawai dalam sebuah organisasi menjadi perhatian penting dalam rangka usaha mencapai keberhasilan organisasi. Keberhasilan suatu organisasi dalam mencapai tujuan organisasi ditentukan oleh kinerja pegawai. Kemampuan pegawai mengerjakan pekerjaan menjadi tanggung jawabnya menjadi tolak ukur pencapaian tujuan organisasi (Ayer, 2016). Apabila suatu organisasi mampu mencapai tujuan yang telah ditetapkan, maka dapat dikatakan bahwa organisasi tersebut efektif. Seiring dengan berkembangnya waktu, semua organisasi dituntut untuk dapat bersaing memberikan pelayanan yang terbaik, termasuk organisasi pemerintah.

meningkatkan kinerja pegawai. Karena suatu sistem informasi akuntansi dirancang untuk menghasilkan informasi keuangan yang digunakan untuk para pemakainya dalam proses pengambilan keputusan didalam suatu organisasi. Pelaksanaan sistem yang handal harus di dukung oleh sumber daya manusia yang berkualitas agar sistem tersebut berjalan sebagaiman mestinya, Keberhasilan pengembangan sumber daya yang berkualitas harus memiliki kinerja yang baik dan kinerja pegawai itu dapat meningkat apabila salah satu 
faktor yang mempengaruhi kinerja adalah motivasi. Pegawai bagian keuangan dituntut untuk memiliki kinerja yang maksimal agar menciptakan hasil kinerja yang baik dan berdampak pada kinerja pemerintah khususnya penyampaian informasi sebagaimana tugasnya dalam pengelolaan dan pelaporan keuangan atas Satuan Kerja Perangkat Daerah (SKPD) yang dinaunginya. Menurut Hasibuan (2003:95) motivasi berasal dari kata latin "movere" yang berarti "dorongan" atau daya penggerak. Dengan motivasi diharapkan setiap individu pegawai mau bekerja keras dan antusias untuk mencapai produktivitas kerja yang tinggi.

Motivasi adalah pemberian daya penggerak yang menciptakan kegairahan kerja seseorang, agar mereka mau bekerja sama, bekerja efektif dan terintegrasi dengan segala daya upayanya untuk mencapai kepuasan. Motivasi itu sendiri bisa timbul dari rangsangan internal atau rangsangan dari eksternal. Rangsangan eksternal motivasi bisa dilakukan pimpinan terhadap pegawainya, hal yang harus disadari oleh pimpinan dalam memotivasi bahwa orang akan mau bekerja keras dengan harapan, ia akan dapat memenuhi kebutuhan dan keinginan-keinginannya. Hal ini juga didukung oleh penelitian Windy dan Gunasti (2012) yang menunjukkan motivasi berpengaruh signifikan terhadap kinerja pegawai.

Faktor lain yang juga memegang peranan penting dalam pelaksanaan kerja pegawai adalah disiplin kerja. Disiplin kerja menurut Alex (1996) menyatakan bahwa disiplin adalah suatu sikap, tingkah laku, dan perbuatan yang sesuai dengan peraturan perusahaan baik yang tertulis maupun tidak. Disiplin juga adalah kesadaran dan kesediaan seseorang menaati semua peraturan dan norma-norma sosial yang berlaku. Kedisiplinan pegawai dapat dilihat dari bagaimana tanggung jawab, sikap, tingkah laku serta perbuatan pegawai dalam mematuhi segala bentuk peraturan selama mereka bekerja pada instansi. Disiplin kerja yang dimiliki oleh pegawai dapat mempengaruhi kinerjanya, ini sama halnya seperti hasil penelitian Dewi Wahyu (2008) yang menunjukkan bahwa semakin baik sikap disiplin kerja yang dimiliki berdampak pada kinerjanya.

Kabupaten Tulungagung sendiri mendapat opini selama tiga tahun berturut-turut pada tahun 2013,2014 dan 2015 opini Wajar tanpa Pengecualian (WTP). Dasar dari penilaian itu sendiri adalah penyajian laporan keuangan yang wajar. Ini menunjukkan bahwa kinerja dari pegawai bagian keuangan pada Satuan Kerja Perangkat Daerah Kabupaten Tulungagung baik, dengan adanya hal tersebut maka peneliti ingin menguji apa faktor-faktor yang mempengaruhi kinerja pegawai bagian keuangan pada Satuan Kerja Perangkat Daerah Kabupaten Tulungagung.

\section{PENGEMBANGAN HIPOTESIS}

1. Pengaruh Pemahaman Sistem Informasi Akuntansi Terhadap Kinerja Pegawai

Teknologi informasi yang diimplementasikan dalam organisasi seharusnya dapat memberikan manfaat pada kinerja individu dan organisasi serta memberikan kenyamanan bagi pemakainya (Wuryaningrum, 2007). Teknologi informasi merupakan salah satu sumber daya penting dalam organisasi. Pemanfaatan teknologi informasi sangat dipengaruhi oleh sumber daya manusia (SDM) yang dimiliki organisasi tersebut. Beberapa penelitian mengenai sistem informasi terhadap kinerja individu yang telah dilakukan sebelumnya, diantaranya adalah penelitian yang dilakukan oleh Mudjiati (2008) dan Astuti 
(2008) menyatakan bahwa sistem informasi memiliki pengaruh positif terhadap kinerja individu. Berdasarkan uraian tersebut, maka dapat dirumuskan sebagai berikut:

H1 : Pemahaman Sistem Informasi Akuntansi berpengaruh terhadap kinerja pegawai bagian Keuangan Satuan Kerja Perangkat Daerah (SKPD) Kabupaten Tulungagung.

\section{Pengaruh Motivasi Terhadap Kinerja Pegawai}

Menurut Riyadi (2000:49), menyatakan bahwa "Motivasi dapat membangkitkan kinerja pegawai untuk bekerja lebih baik. Seorang manajer atau pimpinan yang memiliki motivasi yang tinggi akan mempengaruhi kinerja menjadi lebih tinggi. Apabila motivasi seorang pegawai terhadap pekerjaannya rendah maka akan mempengaruhi kinerja pegawai yang menjadi rendah. Sebaliknya apabila motivasi seorang pegawai tinggi maka mempengaruhi kinerja pegawai menjadi tinggi. Sehingga dapat disimpulkan bahwa motivasi mempunyai pengaruh terhadap kinerja pegawai.

H2 : Motivasi berpengaruh terhadap kinerja pegawai bagian Keuangan Satuan Kerja Perangkat Daerah (SKPD) Kabupaten Tulungagung.

\section{Pengaruh Disiplin Kerja Terhadap Kinerja Pegawai}

Teori organisasi human relations menyatakan bahwa hubungan antara seseorang dengan orang lain dalam suatu organisasi atau kantor, yang bertujuan memberikan kepuasan hati para pegawai, sehingga para pegawai mempunyai semangat kerja yang tinggi, kerjasama yang tinggi, serta disiplin yang tinggi. Disiplin yang tinggi dapat meningkatkan kinerja karena pegawai yang mempunyai disiplin akan sadar dan bersedia bertanggung jawab atas kinerjanya, sehingga pegawai mempunyai rasa disiplin kerja atau tidak, akan menjadi umpan balik yang akan mempengaruhi kinerja pegawai pada suatu instansi, dan seterusnya akan mempengaruhi pula kinerja pegawai tersebut di waktu yang akan datang.

H3 : Disiplin Kerja berpengaruh terhadap kinerja pegawai bagian Keuangan Satuan Kerja Perangkat Daerah (SKPD) Kabupaten Tulungagung.

\section{METODE}

Penelitian ini digunakan dalam penelitian adalah asosiatif dengan objek Satuan Kerja Perangkat Daerah (SKPD) Kabupaten Tulungagung. Pemilihan sampel berdasarkan metode purposive sampling yaitu pegawai bagian keuangan Satuan Kerja Perangkat Daerah (SKPD) Kabupaten Tulungagung. Jenis data yang digunakan adalah data primer. Data tersebut diperoleh dari hasil penyebaran kuesioner pada pegawai bagian keuangan Satuan Kerja Perangkat Daerah (SKPD) Kabupaten Tulungagung.

Variabel independen dalam penelitian ini adalah pemahaman sistem informasi akuntansi, motivasi, dan disiplin kerja yang mempengaruhi variabel dependen yaitu kinerja pegawai. Indikator setiap variabel diukur menggunakan skala pengukuran interval yaitu skala likert yang memiliki rentang skala 5 tingkatan, tetapi dimodifikasi menjadi 4 tingkatan menghilangkan jawaban yang 
ditengah yaitu ragu-ragu yang memiliki skor 3 untuk menghindari jawaban rancu.

Penelitian ini menggunakan bantuan SPSS 22.0 untuk menganalisis data dan menguji hipotesis. Tahapan dalam menganalisa data pada penelitian ini adalah sebagai berikut:

1. Analisis Deskriptif

Untuk mengetahui atau menggambarkan profil sampel yang dipilih digunakan metode statistik secara umum, yaitu analisis deskriptif

\section{Uji Validitas}

Uji validitas adalah menyatakan bahwa sejauh mana data yang ditampung pada kuesioner yang ingin diukur, jadi validitas merupakan suatu ukuran yang menunjukan tingkat kevalidan suatu kuesioner (Ghazali, 2005:45). Apabila nilai $r$ hitung $>$ dari tabel $(\mathrm{P}>0.05)$ data yang dihasilkan tidak valid dan sebaliknya apabila nilai $r$ hitung $<$ dari $r$ tabel atau $(\mathrm{P}<0.05)$ maka data yang dihasilkan valid.

\section{Uji Reliabilitas}

Uji reabilitas digunakan untuk mengukur suatu kuesioner yang merupakan indikator-indikator dari variabel bebas dan variabel tergantung. Dalam penelitian ini menggunakan teknik dari Cronbach Alpha untuk mengukur reabilitas dari sebuah konstruk atau variabel. Suatu konstruk dikatakan reliable jika memberikan nilai Cronbach Alpha lebih besar dari 0.60 (Ghazali, 2005:42).

4. Melakukan Uji Normalitas

Kualitas data diuji dengan Uji Normalitas. Pengujian Normalitas data dilakukan dengan Kolmogorov Smirnov. Pengujian ini dilakukan untuk mengetahui distribusi data. Jika nilai signifikasi lebih besar dari 0,05 maka data terdistribusi dengan normal, dan jika kurang dari 0,05 maka data terdistribusi dengan tidak normal.

5. Data diolah dengan menggunakan cara statistik dalam bentuk Regresi Linier Berganda dengan rumus :

$$
\mathrm{Y}=\beta_{0}+\beta_{1} \mathrm{X}_{1}+\beta_{2} \mathrm{X}_{2}+\beta_{3} \mathrm{X}_{3}+\mathrm{e}
$$

Dimana :

$$
\begin{aligned}
& \mathrm{Y} \quad=\text { Kinerja Pegawai } \\
& \mathrm{X} 1=\text { Pemahaman Sistem Informasi Akuntansi } \\
& \mathrm{X}_{2} \quad=\text { Motivasi } \\
& \text { X3 }=\text { Disiplin Kerja } \\
& \text { Bo } \quad=\text { Konstanta } \\
& \mathrm{B}_{1} \mathrm{~B}_{2} \mathrm{~B}_{3}=\text { Koefisien regresi masing-masing variabel } \mathrm{X} 1, \mathrm{X} 2, \mathrm{X} 3 \\
& \text { e } \quad=\text { Variabel Penganggu }
\end{aligned}
$$

\section{HASIL DAN PEMBAHASAN}

1. Statistik Deskriptif

Berikut adalah hasil dari uji statistik deskriptif. 
Tabel 1. Hasil Statistik Deskriptif

\begin{tabular}{lccccc}
\hline & N & Minimal & Maksimal & Mean & $\begin{array}{c}\text { Std. } \\
\text { Deviation }\end{array}$ \\
\hline Pemahaman SIA & 70 & 23 & 35 & 27.83 & 2.071 \\
Motivasi & 70 & 39 & 58 & 44.33 & 3.590 \\
Disiplin Kerja & 70 & 23 & 36 & 28.54 & 2.636 \\
Kinerja Pegawai & 70 & 22 & 36 & 27.59 & 2.482 \\
\hline
\end{tabular}

Sumber : data diolah 2018

Tabel 1 diatas Variabel pemahaman sistem informasi akuntansi diperoleh rata-rata 27.83, nilai maksimum 35, dan nilai minimum 23. Standar deviasi sebesar 2.071 lebih kecil dari nilai mean dan menjauhi angka o sehingga dapat dikatakann bahwa penyebaran data cukup beragam.

Variabel motivasi mempunyai nilai rata-rata sebesar 44.33, nilai maksimum 58, dan nilai minimum 39. Standar deviasi menunjukkan ukuran variasi data terhadap mean dengan nilai 3.590.

Variabel disiplin kerja diperoleh rata-rata sebesar 28.54, nilai maksimum 36, nilai minimum 23, sedangkan standar deviasi menunjukkan ukuran variasi data terhadap mean dengan nilai 2.636 .

Variabel kinerja pegawai diperoleh rata-rata sebesar 27.59 mempunyai nilai maksimum 36 dan nilai minimum 22. Standar deviasi menunjukkan ukuran variasi data terhadap mean dengan nilai 2.482 .

2. Uji Validitas

Untuk melakukan uji validitas, digunakan penelitian statistic correlative bivariate, dengan nilai signifikansi lebih kecil dari 0.05 maka butir pertanyaan adalah valid. Apabila nilai signifikansi lebih dari 0.05 maka butir pertanyaan adalah tidak valid (Imam Ghazali, 2005:45).

Tabel 2 Hasil Pengujian Validitas Variabel Pemahaman Sistem Informasi Akuntansi (X1)

\begin{tabular}{|c|c|c|c|}
\hline $\begin{array}{c}\text { Item } \\
\text { Pertanyaan }\end{array}$ & Nilai korelasi & Signifikansi & Keterangan \\
\hline 1 & 0.395 & 0.001 & Valid \\
\hline 2 & 0.419 & 0.000 & Valid \\
\hline 3 & 0.405 & 0.001 & Valid \\
\hline 4 & 0.466 & 0.000 & Valid \\
\hline 5 & 0.586 & 0.000 & Valid \\
\hline 6 & 0.574 & 0.000 & Valid \\
\hline 7 & 0.478 & 0.000 & Valid \\
\hline 8 & 0.461 & 0.000 & Valid \\
\hline 9 & 0.706 & 0.000 & Valid \\
\hline
\end{tabular}

Sumber : Data diolah 2018

Tabel 3. Hasil Pengujian Validitas Variabel Motivasi (X2) Putaran 1

\begin{tabular}{|c|c|c|c|}
\hline $\begin{array}{c}\text { Item } \\
\text { Pertanyaan }\end{array}$ & Nilai Korelasi & Signifikansi & Keterangan \\
\hline 1 & 0.288 & 0.016 & Valid \\
\hline 2 & 0.578 & 0.000 & Valid \\
\hline 3 & 0.623 & 0.000 & Valid \\
\hline
\end{tabular}




\begin{tabular}{|c|c|c|c|}
\hline 4 & 0.124 & 0.305 & Tidak Valid \\
\hline 5 & 0.162 & 0.179 & Tidak Valid \\
\hline 6 & 0.534 & 0.000 & Valid \\
\hline 7 & 0.535 & 0.000 & Valid \\
\hline 8 & 0.450 & 0.000 & Valid \\
\hline 9 & 0.547 & 0.000 & Valid \\
\hline 10 & 0.447 & 0.000 & Valid \\
\hline 11 & 0.433 & 0.000 & Valid \\
\hline 12 & 0.619 & 0.000 & Valid \\
\hline 13 & 0.393 & 0.001 & Valid \\
\hline 14 & 0.455 & 0.000 & Valid \\
\hline 15 & 0.340 & 0.004 & Valid \\
\hline
\end{tabular}

Sumber : data diolah 2018

Berdasarkan tabel 3 diketahui bahwa item pertanyaan 4 dan 5 tidak valid karena mempunyai nilai signifikansi lebih dari 0.05, sehingga item pertanyaan tersebut dinyatakan gugur dan tidak digunakan dalam proses analisis. Setelah item pertanyaan yang tidak valid dikeluarkan, selanjutnya dilakukan pengujian validitas putaran kedua dan diperoleh hasil seperti pada tabel 4 di bawah ini.

Tabel 4 Hasil Pengujian Validitas Variabel Motivasi (X2) Putaran 2

\begin{tabular}{|c|c|c|c|}
\hline Item Pertanyaan & Nilai Korelasi & Signifikansi & Keterangan \\
\hline 1 & 0.288 & 0.016 & Valid \\
\hline 2 & 0.578 & 0.000 & Valid \\
\hline 3 & 0.623 & 0.000 & Valid \\
\hline 6 & 0.534 & 0.000 & Valid \\
\hline 7 & 0.535 & 0.000 & Valid \\
\hline 8 & 0.450 & 0.000 & Valid \\
\hline 9 & 0.547 & 0.000 & Valid \\
\hline 10 & 0.447 & 0.000 & Valid \\
\hline 11 & 0.433 & 0.000 & Valid \\
\hline 12 & 0.619 & 0.000 & Valid \\
\hline 13 & 0.393 & 0.001 & Valid \\
\hline 14 & 0.455 & 0.000 & Valid \\
\hline 15 & 0.340 & 0.004 & Valid \\
\hline
\end{tabular}

Sumber : data diolah 2018

Tabel 5 Hasil Pengujian Validitas Variabel Disiplin Kerja (X3)

\begin{tabular}{|c|c|c|c|}
\hline Item Pertanyaan & Nilai Korelasi & Signifikansi & Keterangan \\
\hline 1 & 0.717 & 0.000 & Valid \\
\hline 2 & 0.500 & 0.000 & Valid \\
\hline 3 & 0.316 & 0.008 & Valid \\
\hline 4 & 0.734 & 0.000 & Valid \\
\hline 5 & 0.528 & 0.000 & Valid \\
\hline 6 & 0.626 & 0.000 & Valid \\
\hline 7 & 0.550 & 0.000 & Valid \\
\hline 8 & 0.640 & 0.000 & Valid \\
\hline 9 & 0.759 & 0.000 & Valid \\
\hline
\end{tabular}

Sumber : data diolah 2018 
Tabel 6 Hasil Pengujian Validitas Variabel Kinerja Pegawai (Y)

\begin{tabular}{|c|c|c|c|}
\hline Item Pertanyaan & Nilai Korelasi & Signifikansi & Keterangan \\
\hline 1 & 0.438 & 0.000 & Valid \\
\hline 2 & 0.357 & 0.002 & Valid \\
\hline 3 & 0.417 & 0.000 & Valid \\
\hline 4 & 0.540 & 0.000 & Valid \\
\hline 5 & 0.658 & 0.000 & Valid \\
\hline 6 & 0.724 & 0.000 & Valid \\
\hline 7 & 0.547 & 0.000 & Valid \\
\hline 8 & 0.572 & 0.000 & Valid \\
\hline 9 & 0.644 & 0.000 & Valid \\
\hline
\end{tabular}

Sumber : data diolah 2018

3. Uji Reliabilitas

Hasil dari uji reabilitas instrument ditampilkan pada tabel 7 menunjukkan bahwa hasil pada uji reliabilitas variabel penelitian diketahui nilai cronbach's alpha semua variabel lebih besar dari 0.60, sehingga dapat disimpulkan kuesioner pada masing-masing variabel penelitian dapat dinyatakan telah handal dan dipercaya sebagai alat ukur yang menghasilkan jawaban yang relatif konsisten.

Tabel 7. Hasil Uji Reliabilitas

\begin{tabular}{|c|c|c|}
\hline Variabel & Cronbach's Alpha & Keterangan \\
\hline Pemahaman SIA & 0.708 & Reliabel \\
\hline Motivasi & 0.713 & Reliabel \\
\hline Disiplin kerja & 0.747 & Reliabel \\
\hline Kinerja pegawai & 0.730 & Reliabel \\
\hline
\end{tabular}

Sumber : data diolah 2018

4. Uji Normalitas

Uji normalitas dapat dilakukan menggunakan uji kolmogorov-smirnov (k-s). Jika hasil k-s mempunyai nilai > 0.05 maka dapat dikatakan normal. Berdasarkan tabel 8 terlihat bahwa nilai kolmogorov-smirnov sebesar 0.684 dengan tingkat signifikan 0.738, berarti hal itu menunjukkan bahwa model regresi terdistribusi normal karena tingkat signifikansi $>0.05$.

Tabel 8. Hasil Uji Normalitas

\begin{tabular}{|c|c|c|}
\hline & Unstandardized Residual & \multirow{2}{*}{ Keterangan } \\
\cline { 1 - 2 } Kolmogorov-Smirnov & .684 & \multirow{2}{*}{ Normal } \\
\cline { 1 - 2 } Nilai Signifikansi & .738 & \\
\hline
\end{tabular}

Sumber : data diolah 2018

5. Analisis Regresi Linear Berganda

Teknik analisis pada penelitian ini menggunakan regresi linier berganda, hasil perhitungan dengan bantuan progam SPSS 22.0 dan diperoleh hasil sebagai berikut:

Tabel 9.Hasil Analisis Regresi

\begin{tabular}{|l|c|c|}
\hline \multicolumn{1}{|c|}{ Variabel } & Koefisien Regresi & Standar Error \\
\hline (Constant) & 5.434 & 3.764 \\
Pemahaman SIA $\left(\mathrm{X}_{1}\right)$ & 0.142 & 0.126 \\
\hline
\end{tabular}




\begin{tabular}{|l|l|l|}
\hline Motivasi $\left(\mathrm{X}_{2}\right)$ & 0.215 & 0.075 \\
Disiplin Kerja $\left(\mathrm{X}_{3}\right)$ & 0.353 & 0.104 \\
\hline $\mathrm{R}=0.628$ & \\
$\mathrm{R}$ Square $=0.394$ & & \\
Adjusted R Square $=0.366$ & & \\
\hline
\end{tabular}

Sumber : data diolah 2018

Berdasarkan Tabel 4.18 dapat dibuat persamaan regresi sebagai berikut: $\mathrm{Y}=5.434+0.142 \mathrm{X} 1+0.215 \mathrm{X} 2+0.353 \mathrm{X} 3+\mathrm{e}$

Penjelasan masing-masing koefisien regresi adalah sebagai beikut :

bo $=$ Konstanta $=5.434$

Menunjukkan bahwa besarnya Kinerja Pegawai bagian keuangan pada Satuan Kerja Perangkat Daerah Kabupaten Tulungagung. Artinya apabila pemahaman sistem informasi akuntansi, motivasi dan disiplin kerja sama dengan nol (tidak memberikan pengaruh), maka kinerja pegawai bagian keuangan pada Satuan Kerja Perangkat Daerah Kabupaten Tulungagung adalah sebesar 5.434.

b1 $=$ Koefisien Regresi Untuk Pemahaman SIA $\left(\mathrm{X}_{1}\right)=0.142$

Artinya apabila pemahaman sistem informasi akuntansi naik satu satuan, maka Kinerja Pegawai bagian keuangan pada Satuan Kerja Perangkat Daerah Kabupaten Tulungagung akan naik sebesar 0.142 satuan, dengan asumsi Motivasi dan Disiplin Kerja adalah konstan atau tidak berubah.

$\mathrm{b} 2=$ Koefisien Regresi Untuk Motivasi $(\mathrm{X} 2)=0.215$

Artinya apabila Motivasi naik satu satuan, maka Kinerja Pegawai bagian keuangan pada Satuan Kerja Perangkat Daerah Kabupaten Tulungagung akan naik sebesar 0.215 satuan, dengan asumsi Pemahaman Sistem Informasi Akuntansi dan Disiplin kerja adalah konstan atau tidak berubah.

b3 = Koefisien Regresi Untuk Disiplin Kerja (X3) $=0.353$

Artinya apabila Disiplin Kerja naik satu satuan, maka Kinerja Pegawai bagian keuangan pada Satuan Kerja Perangkat Daerah Kabupaten Tulungagung akan naik sebesar 0.353 satuan, dengan asumsi Pemahaman Sistem Informasi Akuntansi dan Motivasi adalah konstan atau tidak berubah.

\section{Uji Koefisien Determinasi}

Nilai yang digunakan dalam koefisien determinasi adalah dengan menggunakan nilai adjusted $\mathrm{R}^{2}$ yang telah diseuaikan adalah .366 yang menunjukan $36.6 \%$. Sehingga dapat disimpulkan bahwa pemahaman sistem infromasi akuntansi, motivasi, dan disiplin kerja berpengaruh sebesar $36.6 \%$ terhadap kinerja pegawai, sedangkan sisanya $63.4 \%$ dipengaruhi oleh variabel lain. Nilai adjusted $\mathrm{R}^{2}$ yang digunakan, diambil dari tabel model summary dalam tabel 10:

Tabel 10. Hasil Uji Koefisien Determinasi

Model Summary ${ }^{\mathrm{b}}$

\begin{tabular}{|c|c|c|c|c|}
\hline Model & $\mathrm{R}$ & $\mathrm{R}$ Square & $\begin{array}{c}\text { Adjusted R } \\
\text { Square }\end{array}$ & $\begin{array}{c}\text { Std. Error of } \\
\text { the Estimate }\end{array}$ \\
\hline 1 & $.628^{\mathrm{a}}$ & .394 & .366 & 1.975 \\
\hline
\end{tabular}

Sumber : data diolah 2018 


\section{7. $\quad$ Uji Simultan (Uji F)}

Berdasarkan hasil uji simultan (uji F) ANOVA atau $F$ test pada tabel 11 diketahui nilai $\mathrm{F}_{\text {hitung }}$ adalah 14.305 dengan probabilitas 0,000 yang lebih kecil dari tingkat signifikan 0,05 sehingga model regresi layak untuk digunakan. Pengujian lainnya dapat dilakukan dengan membandingkan nilai $F_{\text {_ }}$ hitung dan nilai $F_{\text {tabel }}$ dengan ketentuan jika nilai $F_{\text {hitung }}>$ nilai $F_{\text {tabel }}$ maka variabel independen berpengaruh signifikan terhadap variabel dependen. Berdasarkan tabel diatas diperoleh hasil nilai $F_{\text {hitung }} 14.305>$ nilai $F_{\text {tabel }} 2.74$ yang berarti bahwa pemahaman sistem informasi akuntansi, motivasi, dan disiplin kerja secara simultan berpengaruh signifikan terhadap kinerja pegawai.

Tabel 11. Hasil Uji F

\begin{tabular}{|c|c|c|c|c|c|c|}
\hline \multicolumn{7}{|c|}{ ANOVA $^{b}$} \\
\hline \multicolumn{2}{|c|}{ Model } & $\begin{array}{l}\text { Sum of } \\
\text { Squares }\end{array}$ & Df & Mean Square & $\mathrm{F}$ & Sig. \\
\hline 1 & Regression & 167.457 & 3 & 55.819 & 14.305 & $.000^{\mathrm{a}}$ \\
\hline & Residual & 257.528 & 66 & 3.902 & & \\
\hline & Total & 424.986 & 69 & & & \\
\hline
\end{tabular}

Sumber : data diolah 2018

8. $\quad$ Uji Parsial (Uji t)

Uji t digunakan untuk membuktikan apakah masing-masing variabel bebas yang terdiri dari Pemahaman Sistem Informasi Akuntansi, Motivasi dan Disiplin Kerja secara parsial berpengaruh signifikan terhadap Kinerja pegawai. Hasil perhitsungan dengan menggunakan SPSS 22.0 diketahui hasil uji t dari masing-masing variabel sebagai berikut:

Tabel 12 Hasil Uji t

\begin{tabular}{|c|c|c|c|c|}
\hline Variabel Bebas & B & Std. Error & t Hitung & Sig. \\
\hline Pemahaman SIA & .142 & .126 & 1.129 & 0.263 \\
\hline Motivasi & .215 & .075 & 2.897 & 0.005 \\
\hline Disiplin Kerja & .353 & .104 & 3.389 & 0.001 \\
\hline
\end{tabular}

Sumber : data diolah 2018

a. Pengaruh secara parsial Pemahaman Sistem Informasi Akuntansi

Pemahaman Sistem Informasi Akuntansi secara parsial tidak berpengaruh signifikan terhadap Kinerja Pegawai. Hal tersebut dapat dilihat dalam tabel 4.16 pada nilai koefisien regresi variabel ukuran perusahaan sebesar 0.142 dan nilai $t_{\text {hitung }}$ 1.129. Nilai koefisien regresi tidak signifikan pada tingkat signifikansi 0.05 lebih kecil dari nilai p value sebesar 0.263 dan hipotesis ditolak.

b. Pengaruh secara parsial Motivasi terhadap Kinerja Pegawai

Motivasi secara parsial berpengaruh dengan nilai signifikansi 0.005 terhadap Kinerja Pegawai. Hal tersebut dapat dilihat dalam tabel 4.16 pada nilai koefisien regresi variabel ukuran perusahaan sebesar 0.215 dan nilai thitung 2.897 . Nilai koefisien regresi signifikan pada tingkat signifikansi 0.05 lebih besar dari nilai $p$ value sebesar 0.005 dan hipotesis diterima. 
c. Pengaruh secara parsial Disiplin Kerja Kerja terhadap Kinerja Pegawai. Disiplin Kerja secara parsial berpengaruh signifikan terhadap kinerja pegawai. Hal tersebut dapat dilihat dalam tabel 4.16 pada nilai koefisien regresi variabel ukuran perusahaan sebesar 0.353 dan nilai thitung 3.389. Nilai koefisien regresi signifikan pada tingkat signifikansi 0.05 lebih besar dari nilai $\mathrm{p}$ value sebesar 0.001 dan hipotesis diterima

\section{SIMPULAN}

Berdasarkan penelitian yang telah dilakukan mengenai pengaruh pemahaman sistem informasi akuntansi, motivasi, dan disiplin kerja terhadap kinerja pegawai, menunjukan hasil bahwa pemahaman sistem informasi akuntansi tidak berpengaruh signifikan terhadap kinerja pegawai, sedangkan motivasi dan disiplin kerja berpengaruh signifikan terhadap kinerja pegawai.

\section{DAFTAR PUSTAKA}

Aprilia Murty Dan Hudiwinarsih. 2012. Pengaruh Kompensasi, Motivasi, Dan Komitmen Organisasi Terhadap Kinerja Karyawan Bagian Akuntansi (Studi Kasus Pada Perusahaan Manufaktur Di Surabaya). The Indonesian Accounting Review. Vol. 2, No. 2, 215-228.

Dewi, Yuniarti, Dan Wikrama. 2017. Pengaruh Sistem Informasi Akuntansi Dan Budaya Organisasi Terhadap Kinerja Organisasi Hotel Di Kabupaten Buleleng. E-Journal Akuntansi, Vol. 7, No. 1.

Ghazali, Imam. 2005. Aplikasi Analisis Multivariate dengan Progam SPSS. Semarang: Badan Penerbit Universitas Diponegoro.

Ikhsan, Arfan Dan Muhammad Ishak. 2005. Akuntansi Keprilakuan. Jakarta: Penerbit Salemba Empat.

Malayu S.P Hasibuan. (1997), Manajemen Sumber Daya Manusia. Jakarta: CV. Haji Masagung.

Nur Indrianto, Dan Bambang Supono. 1999. Metodologi Penelitian Bisnis Untuk Akuntansi dan Manajemen. Edisi Pertama. Yogyakarta: BPFE Yogyakarta.

Rizaldi. 2015. Pengaruh Sistem Informasi Terhadap Kinerja Karyawan CV Teguh Utama. Jurnal Ilmu Eं Riset Akuntansi. Vol. 4, No. 1.

Sutrisno. 2013. Pengaruh Disiplin Kerja Dan Motivasi Kerja Terhadap Kinerja Pegawai Negeri Sipil (Studi Di Kantor Dinas Sosial Provinsi Jawa Tengah. Jurnal Ilmiah Dinamika Ekonomi dan Bisnis. Vol. 1, No. 1.

Sumbung, Falah, Dan Antoh. 2017. Pengaruh Motivasi Dan Dispilin Terhadap Pegawai Dengan Pemberian Insentif Sebagai Variabel Moderasi (Studi Kasus Di Sekretariat Daerah Kabupaten Jayawijaya). Jurnal Keuda. Vol. 2, No 1.

Wahyuni Dan Dewi Urip. 2008. Pengaruh Motivasi, Kepemimpinan, Disiplin Kerja Terhadap Kinerja Melalui Perilaku Karyawan Pada Guru SMA Swasta Di Kawasan Surabaya Barat. Ventura. Vol 11, $214-236$. 